\title{
KAPAMALIAN DI DESA KANEKES \\ KECAMATAN LEUWIDAMAR KABUPATEN LEBAK-BANTEN \\ (Ulikan Etnopedagogi)
}

\author{
Muhamad Kusaeri \\ MGMP Kabupaten Pandeglang \\ pos-el: m.kusaeri95@gmail.com
}

\begin{abstract}
Abstrak
Penelitian ini dilatarbelakangi oleh kenyataan kurangnya pemahaman masyarakat umum pada makna dan nilai pendidikan dalam kapamalian yang hidup disekelilingnya. Tujuan dari penelitian ini untuk mendeskripsikan kapamalian yang ada di Desa Kanekes, menjelaskan klasifikasi dan fungsinya, perkembangannya, dan memaparkan nilai-nilai etnopedagogi yang ada dalam kapamalian tersebut. Metode yang digunakan yaitu medtode deskriftif kualitatif. Sumber data dalam penelitian adalah dari tiga informan di Desa Kanekes. Teknik yang digunakan dalam penelitian ini adalah teknik observasi, dan wawancara, serta analisis datanya dengan menggunakan kartu data. Hasil penelitiannya yaitu, pertama ditemukan 140 kapamalian yang ada di Desa Kanekes. Kedua klasifikasinya terbagi kedalam, 24 pamali dasar, 8 pamali untuk barés kolot, 103 pamali untuk umum, dan 5 pamali untuk tamu yang secara umum memiliki fungsi sebagai aturan adat. Ketiga perkembangannya, ada 13 pamali yang termasuk pamali baru. Keempat nilai étnopedagoginya, ada 1 pamali yang berkaitan dengan moral manusia dengan Tuhan $(0,8 \%)$, 63 pamali yang berkaitan dengan moral manusia dengan pribadinya (45\%), 22 pamali yang berkaitan dengan moral manusia dengan manusia lainnya (15,7\%), 16 pamali yang berkaitan dengan moral manusia dengan alam $(11,4 \%), 8$ pamali yang berkaitan dengan moral manusia dengan waktu $(5,7 \%)$, dan 30 pamali yang berkaitan dengan moral manusia dalam mencapai kesejahteraan lahir batin (21,4\%). Kesimpulannya, kapamalian yang ada di Desa Kanekes mempunyai peran penting sebagai aturan adat yang dipercaya dan diterapkan oleh masayrakatnya, selain itu pamali mempunyai nilai pendidikan moral bagi masyarakat yang berbasis pada kearifan lokal yang disebut etnopedagogi.
\end{abstract}

Kata kunci: folklor, pamali, etnopedagogi

\section{KAPAMALIAN IN KANEKES VILLAGE LEUWIDAMAR DISTRICT LEBAK-BANTEN REGENCY (Analyzing Ethnopedagogy)}

\begin{abstract}
The background of this research is people's lack understanding towards meaning and value of kapamalian exist around them. The puposed of this research is to describe kapamalian in Kanekes village, explain the classification and its function, the development, and revealing ethno-pedagogical values contained in the Kapamalian. This research employed descriptive qualitative approach. The data were gained from three native villagers in Kanekes village. The employed technique in the research was studi pustaka, observation, interview, and the data analysis was conducted using the data card. The first finding was that there were 140 kapamalian in Kanekes village. Secondly, the classification was divided into 24 basic pamali, 8 pamali for the barés kolot, 103 pamali for the public, and 5 pamali for the guest which basically played as the culture rules. Thirdly, the development, there were 13 new pamali. Fourthly, the ethno-pedagogical value, there was 1 pamali related to humans morality to
\end{abstract}


God (0,8\%), 63 pamali related to human morality with their personality (45\%), 22 pamali related to the human morality to humans $(15,7 \%), 16$ pamali related to human morality to nature $(11,4 \%), 8$ pamali related to the human morality to time $(5,7 \%)$, and 30 pamali related to human morality to their way to achieve prosperity $(21,4 \%)$. Conclusion, kapamalian in Kanekes village plays an important role in regulating the culture which is believed and applied by the people, besides, pamali contains moral value for the people based on the local values namely ethno-pedagogy.

Key word: folklore, pamali, ethnopedagogy

\section{PENDAHULUAN}

Masyarakat yang berada di Desa Kankes Kecamatan Lebak-Banten merupakan masarakat adat Sunda yang sering disebut masyarakat Baduy. Jaro Dainah (dalam Kurnia, 2010 hlm.18) menjelaskan bahwa Kanekes nama desa, Baduy sebutan masyarakatnya, selain itu sebutan yang dibuat oleh masyarakat luar Baduy. Masyarakat Baduy merupakan masyarakat adat Sunda yang masih kukuh menganut ajaran nenek moyangnya. Masyarakat Baduy ter bagi dua, yaitu Baduy Luar dan Baduy Dalam.

Masyarakat Baduy mempunyai aturan khusus dalam mengatur pola kehidupannya sehari-hari. Hal ini diatur dalam sebuah amanat kabuyutan yang disebut Pikukuh Karuhun. Aturan-aturan adat yang dibuat oleh nenek moyang masyarakat Baduy bertujuan untuk mengatur semua tindak perilaku dalam kehidupan masyarakat Baduy. Salah satu dari aturan tersebut adalah kapamalian.

Kapamalian di Baduy diwariskan dari generasi ke generasi secara lisan. Kurnia (2010, hlm. 9) menjelaskan bahwa masyarakat Baduy Dalam, memegang teguh pada semua yang dipamalikan yang sudah dibuat oléh nenek moyangnya. Oleh sebab itu setiap aturan adat yang dibuat oleh leluhurnya, selalu ditaati dan dilaksanakan. Sebagaimana yang dijelaskan oléh Hamidimadja (1998, hlm.
61) bahwa masyarakat Baduy Dalam tidak boléh (dipamalikan) berpacaran di hutan, naik kendaraan (motor, mobil, kapal, dsb) karena dapat mendatangkan petaka. Sedikit berbeda dengan masyarakat Baduy Luar yang sudah dipengaruhi oleh modernisasi, yang mengakibatkan beberapa pamalinya sudah tidak berlaku lagi. sebagai mana yang dijelaskan oléh Hamidimadja (1998, hlm. 58) bahwa teu meunang ngala bungbuahan nu aya di kebon batur, bisi bareuh beuteung (tidak boléh mengambil buah di kebut orang lain, karena bisa mengakibatkan perut membengkak). Meskipun begitu, pamali yang sifatnya wajib masih dipercaya dan diterapkan. Terbukti samapai saat ini pamali masih hidup dan selalu diwariskan dari generasi ke generasi.

Pamali merupakan larangan yang dibuat oleh nenek moyang yang diwariskan pada keturunannya. Setiap daerah memiliki pamali yang beragam yang berbeda dengan daerah lainnya, meskipun beberapa pamali mungkin ada yang sama. Sebagai mana yang dijelaskan Hidding (dalam Rahmat K, 2000, hlm. 15) bahwa pamali adalah larangan yang sifatnya tidak logis dan menakut-nakuti yang diwariskan secara turum-temurun dari generasi ke generasi seterusnya. Menakut-nakuti di sini mempunyai arti jika pamali itu dilanggar maka akan mendatangkan celaka atau kena batunya, 
petaka, sampai bisa mengakibatkan kematian yang dialaminya, baik si pelanggar maupun masyarakat sekitarnya. Pamali jika dilihat dari segi arti bukan hanya sekedar istilah yang diucapkan sembarangan, tapi dari pamali tersebut mengandung nilai pendidikan yang mengajarkan secara tidak langsung agar anak-anak menuruti petuah baik yang diucapkan oleh orang tuanya.

Pamali yang tersebar di masyarakat umumnya diklasifikasikan berdasarkan kepada siapa pamali tersebut ditujukan. Sebagaimana yang di jelaskan oleh Mustapa (2010, hlm. 14-19) bahwa pamali diklasifikasi kedalam lima kategori, seperti pamali untuk anak-anak, pamali untuk perawan jeung perjaka, pamali untuk yang sedang mengandung, pamali untuk umum, dan pamali husus untuk satu kelompok saja.

Pamali tergolong kedalam kearifan lokal, sebab pamali dibuat dan dihasilkan dari pengetahuan satu kelompok masyarakat. Isnendes (2014, hlm. 195) menjelaskan bahwa kearifan lokal memiliki sifat abstrak sekaligus kongkret, pedomannya merupakan sistem abstrak, sedangkan dalam praktiknya merupakan sistem yang kongkret. Hal ini sejalan dengan aya dijelaskan oleh Alwasilah (2009, hlmn. 51) bahwa kearifan lokal merupakan proses bagai mana pengetahuan dihasilkan, disimpan, diterapkan, diolah dan diwariskan. Kearifan lokal dijadikan pemebelajaran dalam kehidupan masyarakat, sebab memliki nilai-nilai pendidikan yang disampaikan secara tiadak langsung, seperti halnya dengan pamali.

Nilai-nilai pendidikan yang didasari oleh kearifan lokal tersebut sering disebut etnopedagogi. Sebagaimana yang dijelaskan oleh Alwasilah (2009, hlm. 50) bahwa etnopedagogi merupakan proses pendidikan yang didasari oleh kearifan lokal dalam berbagai hal. Hal-hal tersebut meliputi cara mengobati segala macam penyakit, seni bela diri, lingkangan hidup, sistem pertanian, ekonomi, pemerintahan, sistem perbintangan dan sebaginya. Suryalaga (dalam Sudaryat 2015, hlm. 120) menjelaskan bahwa etnopedagogi didasari oleh nilai-nilai budaya yang meliputi nilai pendidikan, agama, sosial, dan moral. Dari nilai-nilai budaya tadi melahirkan nilai-nilai etnopedagogi yang mencakup paripolah nyunda tri-silas, catur jatidiri insan, panca rawayan atau gapura panca waluya, dan sadrasa kamanusaan. Dalam penelitian ini mendeskripsikan nilai-nilai etnopedagogi sadrasa kamanusaan. Suryalaga (2010, hlm. 17) menjelaskan bahwa sadrasa kamanusaan terdiri dari (1) Moral Manusia terhadap Tuhannya (MMT); (2) Moral Manusia pada Pribadinya (MMP); (3) Moral Manusia pada Manusa lainnya (MMM); (4) Moral Manusia terhadap Alam (MMA); (5) Moral Manusia pada Waktu (MMW); dan (6) Moral Manusia dalam mencapai Kesejahteraan Lahir Batin (MMLB).

Penelitian ini mempunya tujuan untuk mencari dan mendeskripsikan (1) kapamalian di Desa Kanekes Kecamatan Leuwidamar Kabupaten Lebak-Banten; (2) klasifikasi dan fungsi pamali dalam kehiduoan masyarakat di Desa Kanekes Kecamatan Leuwidamar Kabupaten Lebak-Banten; (3) perkembangan kamapalian di Desa Kanekes Kecamatan Leuwidamar Kabupaten Lebak-Banten (4) nilai etnopedagogi sadrasa kamanusaan yang da dalam kapamalian masyarakat Desa Kanekes Kecamatan Leuwidamar Kabupaten Lebak-Banten. 


\section{METODE PENELITIAN}

Penelitian ini menggunakan metode deskriptif dengan menggukan pendekatan kualitatif. Moleong (2006, hlm. 6) menjelaskan bahwa penelitian kualitatif merupakan penelitian yang memiliki tujuan untuk memahami fenomena tentang apa yang dialami oleh subjek penelitian misalnya, perilaku, persepsi, motivasi, jrrd., secara holistik dan menggunakan cara deskripsi dalam bentuk kata-kata dan bahasa, dalam konteks khusus yang alamiah dan memanfaatkan berbagai metode alamiah.

Data dalam penelitian ini adalah kapamalian yang ada di masyarakat Desa Kanekes Kecamatan Leuwidamar Kabupaten Lebak-Bantén. Masyarakat Desa Kanekes yang dikenal dengan sebutan masyarakat Baduy adalah salah satu masyarakat adat Sunda yang masih berpegang teguh pada adat istiadat warisan nenek moyangnya.

Data dikumpulkan melalui teknik observasi, dan wawancara dengan menggunakan instrumen pedoman observasi jeung pedoman wawancara. Data yang didapat dari hasil penelitian diolah memalui analisis data yang meliputi klasifikasi dan fungsi, perkembangan, dan niali-nilai etnopedagogi dalam kapamalian di Desa Kankes dengan menggunakan kartu data.

\section{HASIL DAN PEMBAHASAN}

Berdasarkan hasil analisis pada kapamalian yang ada di Desa Kanekes Kecamatan Leuwidamar Kabupaten Lebak-Banten yang mecakup Baduy Luar dan Baduy Dalam, ditemukan (1) kapamalian di Desa Kanekes, (2) klasifikasi dan fungsi kapamalian, (3) perkembangan kapamalian, dan (4) nilai etnopedagogi yang ada dalam kapamalian di Desa Kanekes.

\section{Kapamalian di Desa Kanekes}

Dalam kehidupan masyarakat tradisonal yang masih percaya terhadap mitos dan hal-hal tabu, biasanya terdapat aturan yang dibuat berdasarkan pada pengalaman nenek moyangnya yang memiliki sifat yang menakut-nakuti. Aturan tersebut dibuat supaya anak cucunya tidak mengalami hal buruk (celaka) yang pernah dialami oleh nenek moyangnya. Begitu juga di tatar Sunda, yang sudah mengenal aturan-aturan yang erat hubungannya dengan mitos serta bersifat menakut-nakuti seperti halnya dengan pamali.

Kapamalian yang ditemukan di Desa Kanekes Kecamatan Leuwidamar Kabupaten Lebak-Banten yang mecakup Baduy Dalam dan Baduy Luar, yaitu ada 140 pamali yang masih hidup di masyarakatnya. Kapamalian tersebut umumnya digunakan untuk mengatur pola hidup masyarakatnya dan tamu yeng berkunjung ke Desa Kanekes Kecamatan Leuwidamar Kabupaten Lebak-Banten, supaya tidak merusak dan merubah tatanan adat leluhurnya. Umumnya pamali yang ada di Baduy Luar pasti ada di Baduy Dalam, sedangkan yang ada di Baduy Dalam belum tentu ada di Baduy Luar. Ada 12 pamali yang hanya berlaku untuk masyarakat Baduy Dalam salah satunya yaitu pamali 'ulah numpak kandaraan, bisi datang mamala' (jangan naik kendaraan, takutnya nanti mendatangkan petaka). Pamali ini tidak berlaku untuk masarakat Baduy Laur, dikarenakan di Baduy Luar diberikan kelonggaran dalam hal aturan adat, namun masih dalam batasan yang wajar. 


\section{Klasifikasi dan Fungsi Pamali di Desa Kanekes}

Klasifikasi pamali dalam penelitian menggunakan dua klasifikasi. Pertama klasifikasi berdasarkan klasifikasi yang telah ada di Desa Kanekes, sebagai mana yang dijelaskan oleh Alim (Ayah Mursid) bahwa pamali di Desa Kanekes dibagi kedalam empat golongan berdasarkan tingkatan hukumannya, yang meliputi pamali dasar, pamali untuk barés kolot, pamali umum, dan pamali untuk tamu. Kedua klasifikasinya berdasarkan kepada siapa pamali tersebut ditujukan. Sebagai mana yang dijelaskan Mustapa (2010, hlm. 14-19) bahwa pamali diklasifikasi berdasarkan beberapa hal, seperti (1) pamali untuk anak-anak; (2) pamali untuk perawan/perjaka; (3) pamali untuk wanita hamil; (4) pamali untuk umum, dan (5) pamali yang sifatnya husus untuk satu kelompok masyarakat.

Berdasarkan klasifikasi pamali yang dilihat dari tingkat hukumannya. Pertama ada 24 pamali dasar yang apabila dilanggar, maka hukumannya dibersihkan dengan cara dimandikan oleh barés kolot, dan diasingkan ke luar Desa Kanekes selama kurun waktu yang ditentukan oleh Puun, salah satunya yaitu pamali, 'parawan jeung jajaka ulah bobogohan, bisi mamala' (perawan dan perjaka jangan berpacaran, takutnya nanti mendatangkan petaka). Pamali ini merupakan salah satu pamali yang jika dilanggar maka akan dihukum sangat berat. Berpacaran di Desa Kanekes merupakan hal yang sangat dilarang, karena berpacaran dapat menjerumuskan manusa kedalam dosa besar.

Kedua ada 8 pamali untuk barés kolot yang apabila dilanggar, maka hukumannya adalah diturunkan dari jabatannya, salah satunya yaitu pamali, 'ulah gorok, bisi hirup karagok' (jangan menipu, takutnya nanti hidupnya menanggung malu). Pamali ini merupakan pamali yang mengharuskan sikap pemimpin di Desa Kanekes untuk tidak menipu rakyatnya, karena pemimpin merupaka sosok yang akan ditiru dan dijadikan contoh bagi masarakatnya.

Ketiga ada 103 pamali untuk umum yang apabila di langgar, hukumannya hanya diberi petuah oleh orang tuanya, salah satunya yaitu pamali, 'budak leutik ulah ngelukkeun sirah batur, bisi jadi polongo' (anak kecil jangan menonyor kepala orang, sebab bisa menjadikannya bodoh). Pamali ini mengajarkan anak kecil agar bersikap sopan dan saling menghargai terhadap orang lain.

Keempat ada 5 pamali untuk tamu yang apabila dilanggra, maka hukumannya hanya diberi peringatan, namun apabila masih melanggar maka akan dilarang datang kembali/diusir dari wilayah adat Desa Kanekes, salah satunya yaitu pamali, 'ulah datang ka Baduy Jero dina bulan kawalu, bisi balikna gering' (jangan berkunjung ke Baduy Dalam saat bulan kawalu, takutnya nanti sakit ketika pulangnya). Pamali ini menyampaikan pesan kepada pengunjung (tamu) untuk dapat menghargai keprcayaan masyarakat Baduy terhadap bulan yang dianggap suci menurut mereka. Bulan kawalu merupakan bulan suci, karena dalam bulan tersebut masyarakat Desa Kanekes menjalankan peribadahannya dengan khusyu.

Berdasarkan klasifikasi yang merujuk pada tiori Mustapa, yang mebagi pamali berdasarkan pada siapa pamali itu ditujukan. Adapun hasilnya seperti di bawah ini.

Pertama ada 33 pamali untuk anakanak, salah satunya pamali, 'budak leutik 
ulah nyésakeun sangu dina piring, bisi meunangkeun pamajikan/salaki nu goréng' (anak kecil jangan menyisakan nasi di piring, takutnya mendapatkan istri/suami yang jelek). Pamali ini menyampaikan sikap sopan dan tanggungjawab. Ketika makan harus dihabiskan dan jangan menyisakannya. Hal ini sesuai dengan adab makan di Baduy, dengan tidak menyisakan makanan, artinya menghargai makanan tersebut.

Kedua ada 10 pamali untuk perawan /perjaka, salah satunya pamali, 'parawan/jajaka ulah dahar dina coét, bisi meunangkeun jodona lamun awéwé ka aki-aki, lamun lalaki ka nini-nini, (perawan/perjaka jangan makan di cobek, takutnya mendapatkan jodoh kakek-kakek bila perempuan, dan nenek-nenek bila laki-laki). Pamali ini mengajarkan tentang sopan sopan santun dan disiplin. Adab makan bisanya menggunakan alas seperti piring. Apabila makan dengan alas cobek merupakan hal yang tidak sopan, karena cobek bukan alas untuk makan.

Ketiga ada 23 pamali untuk wanita hamil, salah satunya pamali, 'nu gedé beuteung ulah saré ti beurang, bisi orokna loba ku kikili' (wanita hamil jangan tidur di siang hari, takutnya bayinya banyak terdapat bercak hitam di kepalanya). Pamali ini mengajarkan kepada wanita hamil untuk jangan sering tidur apalagi di siang hari. Wanita hamil disarankan untuk menjaga kebugarannya, apabila sering tidur di siang hari dapat menurunkan kebugarannya dan bisa berbahaya jika waktu melahirkan tiba.

Keempat ada 50 pamali untuk umum, salah satunya pamali, 'ulah dahar dina kékéncéng, bisi goréng bidang' (jangan makan di wajan, takutnya apapun yang kita lakukan akan selalu terlihat buruk oleh orang lain). Pamali ini mengajarkan untuk disiplin. Ketika makan, ada baiknya menggunakan piring sebagai alas makanan, karena lebih sopan. Apabila makan di wajan, terlihat tidak sopan dan terkesan jorok.

Kelima ada 25 pamali yang sifatnya khusus yang meliputi 12 pamali khusus untuk Baduy Dalam, salah satunya pamali, 'ulah maké alat éléktronik, bisi leungiteun diri' (jangan menggunakan alat elektonik, takutnya kehilangan jatidiri). Pamali ini mengajarkan untuk taat kepada aturan. Menggunakan alat elektronik yang modern dapat mengakibatkan bergesernya norma-norma adat Baduy. Ada 8 pamali untuk barés kolot, salah satunya pamali, 'ulah linyok, bisi dipoyok' (jangan berbohong, takutnya hidup selalu diejek). Pamali ini mengajarkan untuk jujur. Jika berbohong dapat merugikan orang lain, dan jika dikathui kebohongannya makan hidup akan sulit, serta orang-orang akan hilang keparcayaannya. Serta 5 pamali untuk tamu, salah satunya pamali, 'ulah midio atawa popotoan di Baduy Jero, bisi cilaka' (jangan merekam baik video maupun poto di Baduy Dalam, takutnya timbul celaka). Pamali ini mengajarkan agar manusia dapat bijak dalam mengeksplorasi suatu kesukuuan adat salah satunya adalah kesukuuan Baduy.

Dalam klasifikasi ini ada satu pamali yang ada di dua kategori yaitu pamali 'ulah dahar petis dina waktu peuting, bisi ngabalukarkeun kategeunah haté, jeung lamun ka nu can kawin mah bakal hésé jodo, tapi pikeun nu geus kawin mah bakal paséa baé' (jangan makan petis di malam hari, takutnya menimbulkan keresahan, jika dilakukan oleh yang belum menikah bisa mengakibatkan susah jodohnya, dan jika yang sudah menikah 
akan selalu bertengkar) yang ada di pamali untuk perawan/perjaka dan pamali umum.

Melihat pada fungsinya, pamali di Desa Kanekes memiliki fungsi sebagai aturan adat yang merupakan bagian dari pukukuh karuhun yang tidak boleh dilanggar oleh masyarakatnya. Selain itu, pamali juga dijadikan pengajaran pendidikan moral yang diajarkan sejak dini di setiap generasi. Sebagaimana yang dijelaskan oleh salah satu informan, Alim (Ayah Mursid) bahwa pamali merupakan pengajaran moral dalam kehidupan masyarakat Desa Kanekes, agar tidak meninggalkan adat yang dititipkan oleh nenek moyangnya. Hal ini sejalan dengan pendapat Mustapa (2010, hlm. 6-7) bahwa pamali hidup turun-temurun sebagai pengajaran untuk masyarakatnya agar tidak mengalami hal-hal yang dianggap membahayakan. Pamali diajarkan ke generasi mudanya melalui orang tuanya masing-masing dan dari ketua adat pada waktu tertentu.

\section{Perkembangan Kapamalian di Desa Kanekes}

Perkambangan jaman dewasa ini, bagaimanapun juga dapat mempengaruhi pada kehidupan masyarakat Desa Kanekes. Apalagi di masyarakat yang ada di wilayah adat Baduy Luar, meskipun tidak semua pengaruh luar masuk. Supaya pengaruh buruk yang dapat merusak adat dan alam titipan nenek moyangnya tidak tergerus oleh modernisasi, maka dibuatlah kapamalian-kapamalian baru yang menyesuaikan dengan perkembangan jaman.

Kapamalian tidak sertamerta dibuat hanya untuk mengatur pola hidup (kelakuan) masyarakat Desa Kanekes, tapi disamping itu, ada keinginan para barés kolot untuk mengajarkan pada masyarakatnya agar peduli terhadap lingkungannya. Kehidupan masyarakat Desa Kanekes yang tak lepas dari alam, dan lingkungan sosialnya. Apabila masyarakatnya tidak bisa menjaganya, tentu akan rusak merugikan masyarakatnya sendiri serta dapat menimbulkan hal-hal yang tidak diinginkan, misalnya saja perang antar kampung.

Ada 13 pamali yang bisa disebut pamali baru di Desa Kanekes, sebab pamali tersebut berhubungan dengan halhal yang sifatnya baru (modern), misalnya pamali 'ulah nyeuseuh maké sabun, bisi datang mamala ka lembur' (jangan mencuci menggunakan sabun, takutnya datang petaka ke kampung). Sabun merupakan barang/hal yang baru untuk masyarakat Desa Kanekes. Latar belakang dibuatnya pamali yang berhubungan dengan sabun, disebabkan karena sabun memiliki dampak negatif untu keberlangsungan hidup masyarakat Desa Kanekes dalam hal ekologi sungai. Masyarakt Desa Kanekes yang tidak lepas dari kebutuhan terhadap air bersih, dapat dilihat dari posisi setiap kampungnya selalu berdekatan dengan sumber air atau sungai. Apabila sungainya tercemar oleh zat kimia dari sabun, maka akan membuat masyarakat Desa Kanekes kesulitan dalam memenuhi kebutuhan sumber air bersihnya.

\section{Nilai-nilai Etnopedagogi dalam Kapamalian di Désa Kanékés}

Setiap pamali yang ada di Desa Kanenes menempati satu nilai etnopedagogi sadrasa kamanusaan. Suryalaga (2010, hlm. 17) menjelaskan bahwa sadrasa kamanusaan terdiri dari (1) moral manusia terhadap Tuhannya; (2) moral manusia pada pribadinya; (3) moral 
manusia pada manusa lainnya; (4) moral manusia terhadap alam; (5) moral manusia pada waktu; dan (6) moral manusia dalam mencapai kesejahteraan lahir batin (MMLB). Berdasrkan hasil analisisnya, nilai etnopedagogi yang ada pada kapamalian di Desa Kanekes, seperti di bawah ini:

\section{Moral Manusia dengan Tuhannya}

Ada 1 pamali $(0,8 \%)$ yang berhubungan dengan moral manusia dengan Tuhannya yaitu pamali 'ulah datang ka hulu Ciujung, bisi maot' (jangan datang ke hulu sungai Ciujung, takutnya meninggal). Pamali ini menyampaikan moral manusia terhadap Tuhannya dalam hal religi (kepercayaan). Hulu sungai Ciujung merupakan tempat dikeramatkan, sebab di sana ada Sasaka Domas yang merupakan kiblatnya masyarakat Desa Kanekes. Tidak sembarang orang bisa ke tempat itu, hanya Puun tangtu yang pernah datang ke tempat tersebut. Pamali menyampaikan sikap bahwa seluruh tempat ibadah kepada Tuhan merupakan tempat suci (sakral), maka dilarang bagi setiap orang yang tidak memiliki niat mendekatkan diri/beribadah mendatangi tempat tersebut.

\section{Moral Manusia dengan Pribadinya}

Ada 63 pamali (45\%) yang berhubungan dengn moral manusia dengan pribadinya, salah satunya pamali 'budak leutik ulah babaju bari leumpang, bisi naon anu dipikahayangna teu kalaksana' (anak kecil jangan memakai baju sambil berjalan, takutnya apa yang diinginkannya tidak terlaksana). Pamali ini menyampaikan moral manusia pada pribadinya dalam hal disiplin. Apabila sedang memakai baju harus diuk atau diam, tidak sambil melakukan kegiatan lain seperti berjalan, karena dapat mencelakai diri sendri dan orang lain.

\section{Moral Manusia dengan Manusia}

Ada 22 pamali $(15,7 \%)$ yang berhubungan dengan moral manusia dengan manusia lainnya, salah satunya pamali 'ulah monggol tonggong budak, bisi teunggar kalongeun' (jangan memukul punggung anak, takutnya jadi sering melamun). Pamali ini menyampaikan moral manusia dengan manusa lainnya dalam hal salingmenyayangi. Memukul (monggol) punggung anak termasukkedalam perilaku yang tidak baik, dan termasuk kedalam kekerasan terhadap anak. Kekerasan terhadap anak dapat berdampak buruk bagi psikologisnya, oleh karena itu orang dewasa dilarang melakukan kekerasan terhadap anak.

\section{Moral Manusia dengan Alam}

Ada 16 pamali $(11,4 \%)$ yang berhubungan dengan moral manusia terhadap alam, salah satunya yaitu pamali 'ulah asup ka leuweung kolot, bisi dihakan maung' (jangan masuk ke hutan larangan, takutnya dimakan harimau). Pamali ini menyampaikan moral manusia terhadap alam dalam hal menjaga ekologi. Leuweung kolot merupakan nama hutan larangan di Desa Kanekes yang sudah semestinya dijaga baik ekologi maupun ekosistemna. Di leuweung kolot masih terdapat banyak pepohonan dan hewan yang langka. Oleh karena itu, baik masyarakat Desa Kanekes maupun masyarakat umum yang di luar dilarangan masuk ke leuweung kolot, demi menjaga kelestarian hutan tersebut. 


\section{Moral Manusia dengan Waktu}

Ada 8 pamali $(5,7 \%)$ berhubungan dengan moral manusia pada waktu, salah satunya pamali 'parawan ulah ninun jeung ngaput ti peuting, bisi pondok kana umur' (perawan jangan menenun di malam hari, takutnya usianya jadi pendek). Pamali ini menyampaikan moral manusia kana waktu dalam hal disiplin terhadap waktu. Malam, bukan waktu untuk bekerja/berkegiatan seperti menenun yang membutuhkan keteitian. Apabila menenun di malam hari dapat membahayakan penenun, dan dapat menggangu orang yang sedang tidur, karena mesin tenun tradisional seperti yang ada di Desa Kanekes menimbulkan suara yang cukup bising di malam hari.

\section{Moral Manusia dalam mencapai kesejahteraan Lahir Batin}

Ada 30 pamali $(21,4 \%)$ yang berhubungan dengan moral manusia dalam mecapai kesejahteraan lahir batin, salah satunya pamali 'ulah sakola siga urang luar, bisi minteran batur' (jangan sekolah seperti orang luar, takutnya mengakali orang lain). Pamali ini menyampaikan moral manusia dalam mencapai kesejahteraan lahir batin berhubungan etika dalam aturan adat. Sakola formal untuk masarakat Baduy merupakan hal yang dipantrang (dilarang), karena ada ketakutan dari nenek moyangnya jika sekolah formal dapat merusak tatanan adatna dan merubah pola pikir masyarakatnya. Masyarakat Baduy sangat menjaga sekali adat istiadatnya dari dulu hingga kini dan berpegang teguh pada aturan yang dibuat oleh nenek moyangnya. Ketakutan masyarakat Baduy pada sakola formal adalah takut tidak terkontrolnya pengetahuan yang masuk ke pemikiran masyarakat berdampak buruk bagi adat apalagi sampai timbul sifat sombong dengan kepintarannya dan menyalahgunakannya. Sebagai mana yang dijelaskan Alim (Ayah Mursid) dalam wawancara 1 April 2017 bahwa sekolah di luar (formal) dapat merubah pola pikir masyarakat Baduy yang merujuk pada hal yang buruk untuk adat, oleh karena itu pendidikan yang dipakai oleh kita adalah pendidikan yang disampaikan melalui lisan saja seperti pamali, supaya masyrakat memiliki sikap yang baik bagi dirinya dan orang lain serta adat.

Berdasarkan hasil analisis dari nilai etnopedagoginya, kebanyakan pamali berhubungan dengan moral manusia pada pribadunya. Terlihat dalam urusan pamali lebih dominan untuk mengatur perilaku diri pribadi setiap manusia terlebi dahulu sebelum ke hal lainnya, sebab dari diri pribadi akan mempengaruhi hal yang lainnya.

\section{SIMPULAN}

Kapamalian yang ditemukan di Desa Kanekes Kecamatan Leuwidamar Kabupatén Lebak-Banten yaitu berjumlah 140 yang meliputi pamali di Baduy Luar dan pamali di Baduy dalam.

Dalam menentukan klasifikasinya dilakukan dengan menggunkan dua klasifikasi, pertama yang berdasarkan tingkat hukumannya kapamalian di Desa Kanekes terbagi kedalam 24 pamali dasar, 8 pamali untuk barés kolot, 103 pamali untuk umum, dan 5 pamali untuk tamu. Sedikit berbeda dengan klasifikasi kedua yang membagi pamali berdasarkan kepada siapa pamali itu ditujukan. Dalam klasifikasi ini, terdapat 33 pamali untuk anak-anak, 10 pamali untuk perawan/perjaka, 23 pamali untuk wanita hamil, 50 pamali untuk umum, dan 25 pamali yang sifatnya khusus. Pamali di 
Desa Kanekes memiliki fungsi sebagai aturan-aturan adat berhubungan dengan amanat/pikukuh kabuyutan masyarakat Desa Kanekes (Baduy) yang dipercaya dan diterapkan dalam kehidupan masyarakatnya.

Demi menjaga kelestarian adat istiadatnya masyarakat Desa Kanekes mengembangkan kapamaliannya sesuai dengan kebutuhan yang menyasuaikan dengan perkembangan jaman. Fungsi dari pamali selain dijadikan aturan adat di Désa Kanékés, pamali juga dijadikan sumber pendidikan yang mendidik moral masyarakatnya agar tidak melakukan halhal yang dianggap jelek, dan dapat menimbulkan celaka.

Sejalan dengan fungsinya sebagai pendidikan yang berdasar pada kearifan lokal, pamali yang ada di Desa Kanekes memiliki nilai-nilai etnopedagogi sadrasa kamanusaan yang meliputi, moral manusia dengan Tuhannya, moral manusia dengan pribadainya, moral manusia dengan manusia lainnya, moral manusia dengan alam, moral manusia pada waktu, dan moralmanusia dalam mencapai kesejahteraan lahir batinnya. Ada 1 pamali $(0,8 \%)$ berhubungan dengan moral manusia dengan Tuhannya, 63 pamali (45\%) berhubungan dengan moral manusia dengan pribadinya, 22 pamali $(15,7 \%)$ yang berhubungan dengan moral manusia dengan manusia lainnya, 16 pamali $(11,4 \%)$ yang berhubungan dengan moral manusia dengan alam, 8 pamali $(5,7 \%)$ yang berhubungan dengan moral manusia pada waktu, dan 30 pamali $(21,4 \%)$ yang berhubungan moral manusia dalam mencapai kesejahteraan lahir batin. Berdasarkan hasil analisisnya, kebanyakan pamali berhubungan dengan moral manusia dengan pribadinya, sebab perilaku dari diri pribadi mencerminkan sikap setiap manusia, oleh karena itu pamali yang ada di Desa Kanekes kebanyakan dibuat untuk pribadinya sendiri, karena daru diri pribadi akan berpengaruh pada kehidupan yang lainnya.

\section{DAFTAR PUSTAKA}

Alwasilah, A.C, Spk., (2009). Etnopedagogi: Landasan Praktek Pndidikan dan Pendidikan Guru. Bandung: Kiblat Buku Utama.

Hamidimadja, Nurendah. (1998). Sastra Lisan Baduy dan Lingkungan Hidup. Bandug: Yayasan Paraguna Pakuan.

Isnéndés, Rétty. (2014). Estetika Sunda Sebagai Bentuk Kearifan Lokal Masyarakat Sunda Tradisional dalam Sawangan Pendidikan Karakter (Jurnal Pendidikan dan Pengajaran, Vol. 1 No.2). Bandung: Edusentris.

Kurnia, Asep \& Ahmad Sihabudin. (2010). Saatnya Baduy Bicara. Jakarta: PT Bumi Aksara.

Moleong, Lexi J. (2006). Metodologi Penelitian Kualitatof Edisi Revisi (Cetakan ke-22). Bandung: PT. Remaja Rosdakarya Bandung.

Mustapa, Hasan. (2010). Adat Istiadat Sunda. Bandung: PT. Alumni.

Rahmat K., Otong. (2000). Materi Dasar Ilmu Budaya Sunda. Bandung: Universitas Pasundan.

Sudaryat, Yayat. (2015). Wawasan Kasundaan. Bandung: Pendidikan Bahasa Daerah.

Suryalaga, Hidayat. (2010). Filsafat Sunda. Bandung: Yayasan Nur Hidayah. 
UCAPAN TERIMA KASIH

Terima kasih penulis sampaikan

kepada semua pihak yang telah membantu penelitian ini, terutama kepada

Penyunting Jurnal Lokabasa atas

dimuatnya tulisan ini 